1981-04-01

\title{
Multiple Scattering of Protons and Deuterons by Thick Foils
}

D. R. Dixon

G. L. Jensen

S. M. Morrill

C. J. Connors

R. L. Walter

See next page for additional authors

Follow this and additional works at: https://scholarsarchive.byu.edu/facpub

Part of the Electrical and Computer Engineering Commons

\section{Original Publication Citation}

Dixon, D. R., et al. "Multiple Scattering of Protons and Deuterons by Thick Foils." Nuclear Science, IEEE Transactions on 28.2 (1981): 1295-7

\section{BYU ScholarsArchive Citation}

Dixon, D. R.; Jensen, G. L.; Morrill, S. M.; Connors, C. J.; Walter, R. L.; Gould, C. R.; and Thambiduria, P. M., "Multiple Scattering of Protons and Deuterons by Thick Foils" (1981). Faculty Publications. 765. https://scholarsarchive.byu.edu/facpub/765 accepted for inclusion in Faculty Publications by an authorized administrator of BYU ScholarsArchive. For more information, please contact ellen_amatangelo@byu.edu. 


\section{Authors}

D. R. Dixon, G. L. Jensen, S. M. Morrill, C. J. Connors, R. L. Walter, C. R. Gould, and P. M. Thambiduria 
IEEE Transactions on Nuclear Science, Vol. NS-28, No. 2, April 1981

MULTIPLE SCATTERING OF PROTONS AND DEUTERONS BY THICK FOILS

D.R.Dixon, G.L.Jensen, and S.M.Morrill

Department of Physics and Astronomy, Brigham Young University, Provo, Utah 84602

C.J.Connors and R.L.Walter

Department of Physics, Duke University, and Triangle Universities Nuclear Laboratory

Duke Station, Durham, North Carolina 27706

C.R.Gould and P.M.Thambiduria

Department of Physics, North Carolina State University, Raleigh, North Carolina 27607 and

Triangle Universities Nuclear Laboratory

Summary

Protons and deuterons from the Triangle Universities Nuclear Laboratory (TUNL) tandem Van de Graaff of energies 3.0, 4.0, and $5.0 \mathrm{MeV}$ were scattered frow foils of $\mathrm{Al}, \mathrm{Ni}, \mathrm{Mo}$, and $\mathrm{Ta}$ having thicknesses of 6.14 to $47 \mathrm{mg} / \mathrm{cm}^{2}$. Multiple scattering angular distributions were measured using a position-sensitive detector to collect data at nine different angles simultaneously. Gaussian curves were fitted to the central points of the distributions and the $\theta$ /e angles thus derived are presented graphically. The data points are compared with calculations using a common method of determining multiple scattering angles. An empirical correction for extending this method into the low energy and thick foil region considered here is suggested.

\section{Introduction}

An approximate method for calculating the multiple scattering of lons as they pass through folls of material has been made conveniently available by Marion and Young ${ }^{1}$. This method, presented in greater detail in an article by Marion and Zimmerman ${ }^{2}$, is an approximation based on the theory of Nigam, Sundaresan, and $\mathrm{Wu}^{3}$. Multiple-Scattering theories, including the earlier, widely-used theory of Moliere 4,5 are reviewed in a comprehensive article by scott ${ }^{6}$. Marion and Zimmerman indicate that for protons their approxinate method should be valid for $10<\mathrm{E}<1000 \mathrm{MeV}$ and for energy loss in the foll less than $20 \%$ of the initial energy. In some experimental situations, particularly where foils are used in low-energy experiments to degrade the energies of ton beams, these conditions are not net. Because of the uncertainty in the validity

- Supported by U.S. Denartment of Energy and Brigham Young University Research Division

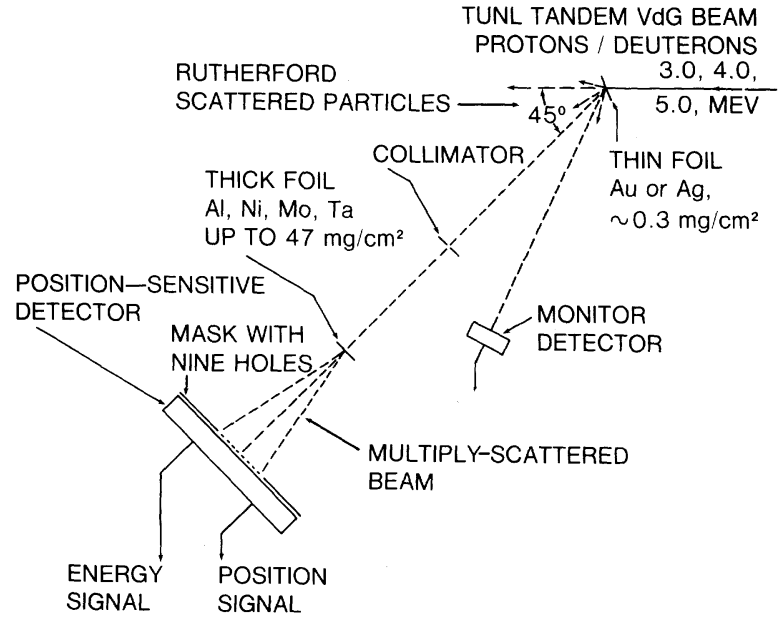

Figure 1 Experimenta1 Arrangement of existing theories and the fact that only a very few measurements ${ }^{7}, 8$ near the region of interest were known, it was decided to make a series of measurements of multiple scattering of low energy ions by thick foils.

\section{Experimental Arrangements}

Proton and deuteron beams of $3.0,4.0$, and 5.0 $\mathrm{MeV}$ energy from the TUNL tandem Van de Graaff accelerator were used in the experiment. The bean was sçattered from a silver foil of about 0.3 $\mathrm{mg} / \mathrm{cm}^{2}$ thickness mounted at the center of a scattering chamber with the normal to the foil at an angle of $22.5^{\circ}$ with respect to the beam as indicated in Figure 1 . The bean size at the foil was $1.0 \mathrm{~mm}$ square. A collimator with a $1.56 \mathrm{~mm}$ diameter hole was placed at approximately $75 \mathrm{~mm}$ from the center of the chamber at an angle of $45^{\circ}$ with respect to the accelerator beam. The low intensity beam formed by this arrangement impinged on the foils under investigation which were mounted at $127 \pm 0.2 \mathrm{~mm}$ frorn the center of the chanber.

A position-sensitive ion-implanted detector having a sensitive area of $25 \times 7 \mathrm{~mm}^{2}$, an energy resolution of $36 \mathrm{keV}$ FWHM for $5.5 \mathrm{MeV}$ alpha particles, and a position resolution of $0.22 \mathrm{~mm}$ FWHM was used to measure the angular distributions. To avoid the necessity of calibrating the position signal, a thin metal mask with a series of nine small holes was placed over the sensitive area of the detector. The holes were of $1.0 \mathrm{~mm}$ diameter spaced on $2.54 \mathrm{~mm}$ centers. The mask was located $178+0.2 \mathrm{~mm}$ from the chamber center. With this arrangement, angular distributions were taken at $2.84^{\circ}$ intervals. In cases where the angular distributions were wide, the detector was rotated $10.5^{\circ}$ to one side of its normal position. In this way measurements were made at additional angles on one side of the distribution.

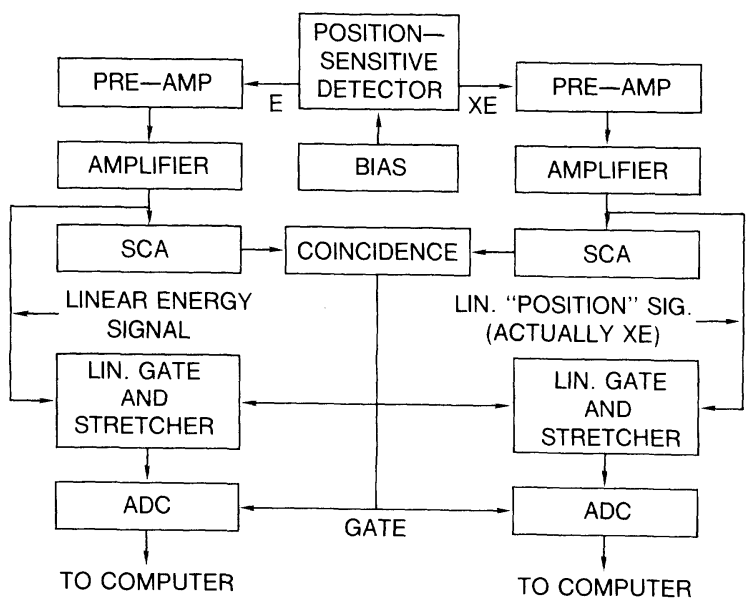

Figure 2 Block Diagram of Electronic Appartus 


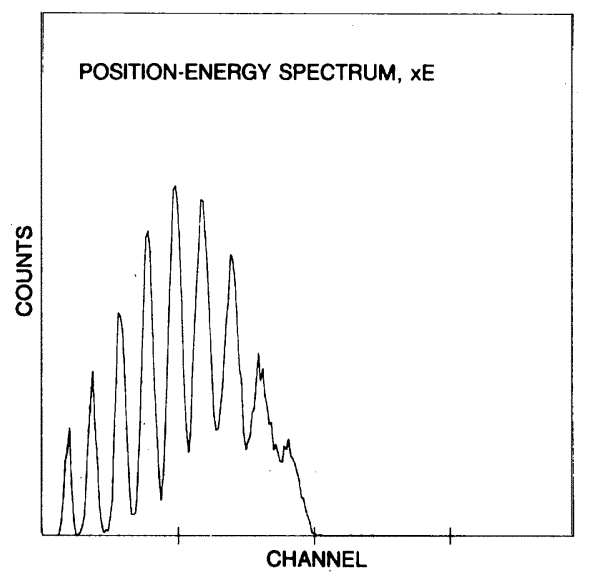

CHANNEL

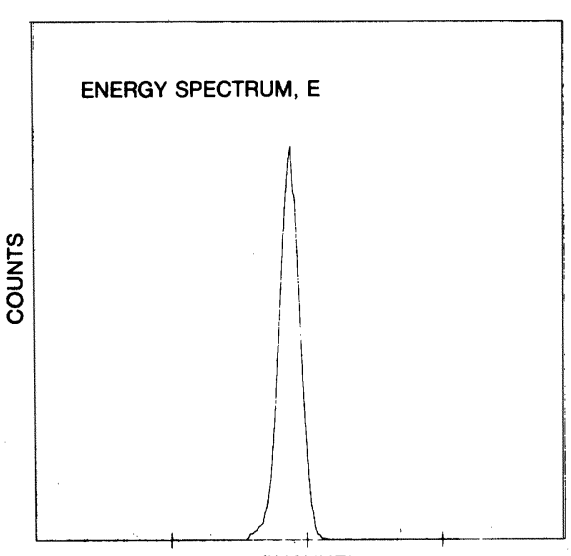

CHANNEL

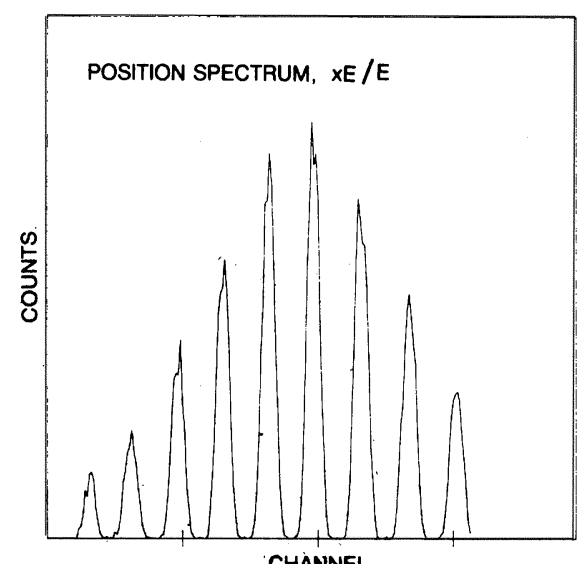

CHANNEL

Figure 3 Spectra of Pulses from the Position-Sensitive Detector

The arrangment of the electronic apparatus is shown in Figure 2. The "position signal" from the detector is actually proportional to both position and particle energy. Fluctuations in energy loss in the scattering foil result in a corresponding smearing out in the position-energy spectrum, as shown in Figure 3. An on-line computer was used to divide the amplitude of the position-energy signal by that of the corresponding energy pulse to produce a true position pulse. Figure 3 shows also an example of a typical energy spectrum and a final position spectrum. The examples shown are for $5.0 \mathrm{MeV}$ deuterons on $47 \mathrm{mg} / \mathrm{cm}^{2}$ tantalum.

Three spectra of this type were taken and stored on magnetic tape for each foil measurement. Single channel analyzer 1 imits were set to allow response to signals in the expected ranges and to reduce response to extraneous signals. A beamcurrent integrator and monttor counter were provided and recordings were made of dead time to assist in nornalizing runs for different detector positions in cases where the scattering angular distributions were broad.

\section{Experimenta1 Procedures}

Readily available foils having a broad range of atomic numbers were selected. Sheets of the foil materials were measured and weighed to determine their areal density. Foil thicknesses were chosen which, in most cases, resulted in relatively large energy losses in the folls.

In a typical scattering measurement an accelerator beam current of 100 to $200 \mathrm{nA}$ and a running time of the order of $5 \mathrm{~min}$ were sufficient to accumulate at least several thousand counts in the central peaks of the angular distribution. At the end of the two-day run, the mask was removed from the position-sensitive detector and some continuous spectra were taken to determine the angular spread of the beam incident on the foils and to assist in calibration of angles.

\section{Treatment of Data and Results}

It is well known that multiple-scattering angular distributions depart appreciably from a Gaussian shape in that the wings are high relative to a Gaussian curve fitted to the points in the central part of the distribution. An example of departure from Gaussian shape is shown in Figure 4 , the measured angular distribution for $5-\mathrm{MeV}$ protons on a $47 \mathrm{mg} / \mathrm{cm}^{2} \mathrm{Ta}$ foll. The data reported here are all given in terms of the width of a Gaussian curve representing the central experimental points.
In the analysis of the data, sums were made of the counts corresponding to particles passing through the different holes in the detector mask. Small corrections were applied to the counts corresponding to some of the holes because of variation in their size as determined by irregularities in Rutherford scattering spectra. Gaussian curves were then fitted to the central points in the spectra. In most cases, to avoid getting into a region where the distribution departs appreciably from the Gaussian shape, only those points above half-maximum were used. From the beam profile measurement with no mask over the position-sensitive detector, it was determined that the beam impinging on the foils had a half width at the $1 / \mathrm{e}$ point of approximately $2.1^{\circ}$. Though the shape of the beam departed somewhat from a Gaussian shape, being flatter on top and having steeper sides than a Gaussian curve, the beam width was roughly accounted for by subtracting it quadratically from the Gaussian curves fitted to the data points. The resultant measured half-angle widths are plotted in Figures 5 and 6.

The particle energies shown are nominal energies of the incident beam. Loss of energy due to recoil of the nuclei and ionization in the silver foll was $70 \mathrm{keV}$ or less. Statistical errors in the experimental points were generally less than $3 \%$. A study of the fitting procedure

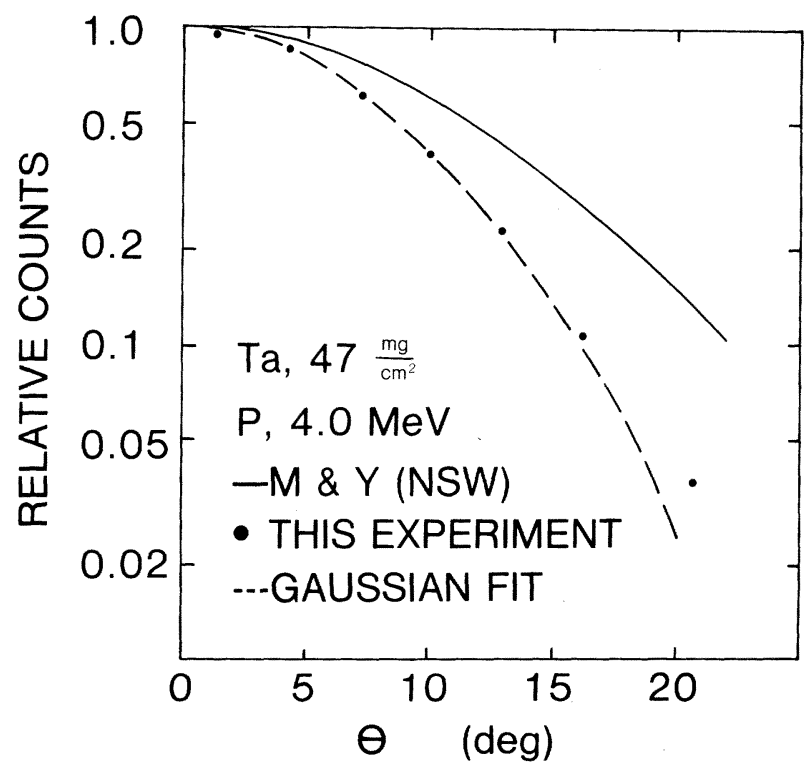

Figure 4 Example of Gaussian Fit and Comparison with $M \& Y$ 

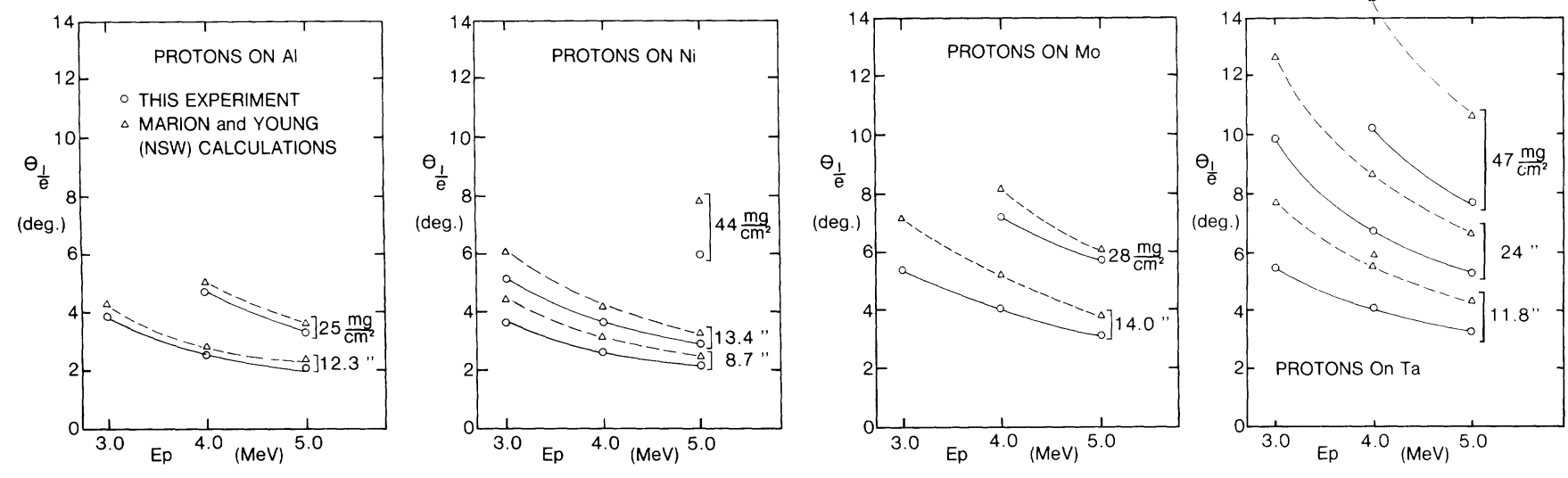

Figure 5 Proton scattering data compared to Marion and Young approximations
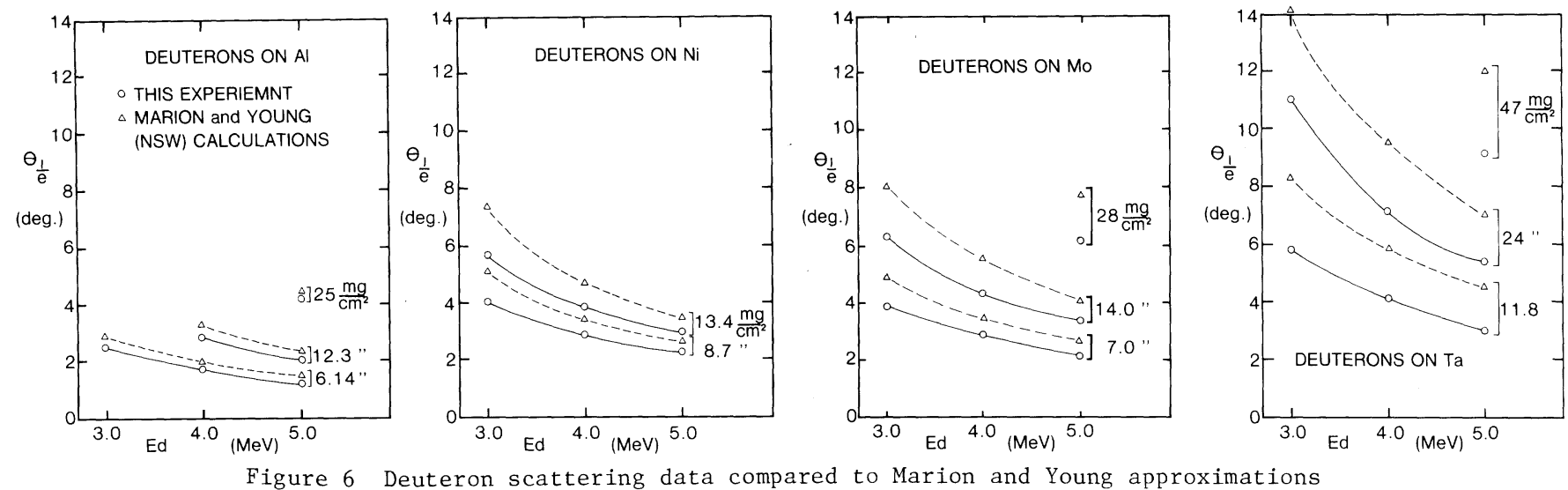

Figure 6 Deuteron scattering data compared to Marion and Young approximations

suggested that the uncertainty in the measured Gaussian widths should not exceed $5 \%$. Considering some tolerances in the arrangement of the apparatus in the scattering chamber, we estimate an overall uncertainty of about $7 \%$ in the angular widths.

\section{Comparison with Other Work}

Calculations of the Marion and Young type using average particle energies are shown in Figures 5 and 6. Lines in these figures are purely for the purpose of helping to visualize the trend of the points. It is seen that our experimental points are lower than the calculated points with differences increasing with increasing $Z$ of the foils and with decreasing energies. These differences are not unexpected considering the fact that our foil thicknesses and particle energies are generally outside the range where the Marion and Young calculations are expected to be valid.

An empirical correction to the Marion and Young calculations by multiplying the $1 / \mathrm{e}$ angle by a factor depending on the atomic number $\mathrm{Z}$ and the incident particle energy $\mathrm{E}$ in $\mathrm{MeV}$ is as follows:

$$
\theta_{1 / \mathrm{e}}=\left(\Theta_{1 / \mathrm{e}}, \mathrm{MY}\right) \mathrm{F}(\mathrm{Z})[1+\mathrm{b}(\mathrm{E}-3)] \text {, }
$$

where $F(Z)=1.024-0.01 Z+8.0 \times 10^{-5} z^{2}$ and

$$
b=-0.013+2.2 \times 10^{-3} z-2.3 \times 10^{-5} z^{2} \text {. }
$$

This procedure yields values within $5 \%$ of the measured $1 / e$ angles in most cases.

Measurements by Bichsel and by Vincour and Bem $^{8}$, while not directly comparable with ours, are reasonably consistent with the results reported here. We agree with Vincour and Bem that the Marion and Zimmernan ${ }^{2}$ correction for energy loss, where the average energy of the particles in the foil is used, is overestimated.

\section{References}

1. J.B. Marion and F.C. Young, Nuclear Reaction Analysis; Graphs and Tables, (American Elsevier Publishing Company, Inc., New York, 1968), pp. 30-33.

2. J.B. Marion and B.A. Zimmerman, Multiple Scattering of Charged Particles, Nucl. Instr. \& Meth. 51, 93 (1967).

3. B.P. Nigam, M.K. Sundaresan and T.Y. Wu, Theory of Multiple Scattering: Second Born Approximation and Corrections to Mollere's Work, Phys. Rev. 115, 491 (1959).

4. G. Moliere, Z. Naturforch. 39, 78 (1948).

5. H.A. Bethe, Moliere's Theory of Multiple Scattering, Phys. Rev. 89, 1256 (1953).

6. W.T. Scott, The Theory of Small-Angle Multiple Scattering of Fast Charged Particles, Rev. Mod. Phys. 35, 231 (1963).

7. H. Bichsel, Multiple Scattering of Protons, Phys. Rev. 112, 182 (1958).

8. J. Vincour and P. Bem, Multiple Scattering of Fast Charged Particles in Silicon, Nucl. Instr. \& Meth. 148, 399 (1978). 